\title{
Organize sanayi bölgesine ait atıksu arıtma tesisinde ECAM modellemesiyle karbon emisyonu değerlendirmesi
}

\author{
Assessment of carbon emission from a wastewater treatment plant of an \\ organized industrial district by ECAM modelling
}

\author{
Cansu Mıstıklar1 (iD, Süreyya Meriç²,*(iD) \\ ${ }^{1}$ Muratl OSB, Tekirdağ, Türkiye \\ 2. Tekirdağ Namık Kemal Üniversitesi, Fen Bilimleri Enstitüsü, Çevre Mühendisliği Bölümü, 59030, Tekirdağ, Türkiye
}

\begin{abstract}
Özet
Günümüzde, iklim değişikliğine etkisi olan faktörlerden biri de atıksu arıtma tesisleridir. Atıksu arıtma tesislerinde meydana gelen temel sera gazı emisyonlar1; karbondioksit $(\mathrm{CO} 2)$, metan $(\mathrm{CH} 4)$ ve nitröz oksit (N2O)'dir. Sera gazı emisyonu, atıksu arıtma tesisindeki işletme prosesi, elektrik tüketimi, çamur arıtımı, bertaraf için taşıma gibi faaliyetlerden kaynaklanmaktadır.
\end{abstract}

$\mathrm{Bu}$ çalışmanın amacı; Tekirdağ'da bulunan karışı atıksuların arıtıldığı bir Organize Sanayi Bölgesine ait atıksu arıtma tesisinde oluşan sera gazı emisyonlarının $(\mathrm{CO} 2, \mathrm{CH} 4, \mathrm{~N} 2 \mathrm{O})$ tahmin edilmesi ve sera gazı emisyonu optimizasyonu yapılmasıdır. Bu çalışmada, sera gazı emisyon hesabı için WaCCliM'in alt organizasyonu olan ECAM web tool programı kullanılmıştır. Çalıșma iki bölümde incelenmiş olup, farklı aylardaki sera gazı emisyonu tahminleri yapılmış ve sonuçları karşılaştırılmıştır. Atıksu debisinin artması ve yük miktarının değişkenliği sonucunda en yüksek emisyon $226.573 \mathrm{kgCO} 2$ eşdeğer/ay ile Aralık ayında oluşmuştur. Yaz aylarındaki sera gazı emisyon sonuçlarına göre en yüksek emisyon 195.174 kgCO2eşdeğer/ay ile Temmuz ayında oluşmuştur. Çalışmadan elde edilen sonuçlara göre arıtma tesislerindeki emisyon kaynağının çoğunluğu elektrik enerjisi tüketimi ve çamur yönetiminden kaynaklandığı görülmüştür. Emisyonların minimize edilmesi için yenilenebilir enerji kaynak kullanımının arttırılması ve çamur bertarafının azaltılması sağlanmalıdır.

Anahtar kelimeler: Sera gazı emisyonu, Atıksu arıtma tesisi, ECAM yazılımı, İklim değişikliği, Enerji verimliliği, Optimizasyon

\section{Giriş}

Sanayileşmenin başladığı dönemden günümüze kadar olan süreçte, sanayi alanındaki ilerlemeler sonucunda kontrolsüz ve bilinçsizce salınan gazlar, kentleşme faaliyetlerinin artışı, çevre kirliliği problemlerinin oluşmasına neden olmakta ve doğal dengenin bozularak iklim değişikliği olaylarına sebep olmaktadır.

Bu kapsamda iklim değişikliği ve çevresel sorunlara çözüm önerilerinin ilk adımları 1992 yılında gerçekleștirilen Rio Konferans1, 1997'de imzaya sunulduktan sonra 2005'te

\begin{abstract}
Nowadays, one of the factors that have an impact on climate change is wastewater treatment facilities. The main greenhouse gas (GHG) emissions are carbondioxide (CO2), nitrous oxide (N2O) and methane (CH4) in waste water treatment plants. GHG emissions are caused by several items such as the electric consumption, treatment process, sludge treatment, sludge transportation for disposal in the WWTP.

The purpose of this paper is the optimization and estimation of GHG emissions from a central wastewater treatment plant in an organized industrial district in Tekirdag. GHG emissions from WWTP have been calculated using ECAM web tool that is designed by $\mathrm{WaCCliM}$ organization. This work analyzed GHG emissions are compared and estimated for different months with in two sections. The highest emissions were estimated in December to be 226.573 $\mathrm{kgCO} 2 \mathrm{eq} / \mathrm{month}$ because the wastewater flow and wastewater load were increased. The highest emission in summer months was estimated to be 195.174 $\mathrm{kgCO} 2 \mathrm{eq} / \mathrm{month}$ for July. The results of this work showed that the most of expenses are spent through electric energy consumption and sludge transportation and disposal in the WWTP. GHG emissions are minimized if it is increased the use of renewable energy sources and is decreased to produce disposal sludges.
\end{abstract}

Keywords: Greenhouse gas emission, Wastewater treatment plant, ECAM web tool, Climate change, Energy efficiency, Optimization

yürürlüğe giren Kyoto Protokolü ve 2015 yılında geniş bir katılım sağlanarak imzalanan Paris Anlaşması'dır.

1992 yilında 3-14 Haziran tarihleri arasında toplanan Birleşmiş Milletler Çevre ve Kalkınma Konferansında (Rio Dünya Zirvesi), United Nations Framework Convention on Climate Change (Birleşmiş Milletler İklim Değişikliği Çerçeve Sözleşmesi-BMIDÇS) imzaya açılmıştır. Bu sözleşmenin amacı; atmosferde serbest haldeki sera gazı birikimlerinin, genel anlamda iklim üzerindeki insan kaynaklı etkisini önleyecek düzeyde başarmaktır. Aynı

\footnotetext{
* Sorumlu yazar / Corresponding author, e-posta / e-mail: smeric@nku.edu.tr (S. Meriç)

Geliș / Recieved: 15.01.2021 Kabul / Accepted: 25.06.2021 Yayımlanma / Published: 27.07.2021

doi:10.28948/ngmuh.862187
} 
zamanda böyle bir başarıya ulaşırken ekosistemin iklim değişikliğine doğal bir şekilde uyum sağlaması, gıda üretiminin zarar görmemesi ve ekonomik kalkınmanın sürdürülebilir şekilde devam etmesi amaçlanmıştır [1].

Kyoto Protokolünde baz alınan gazlar; Karbon dioksit $\left(\mathrm{CO}_{2}\right)$, Metan $\left(\mathrm{CH}_{4}\right)$, Nitroksit $\left(\mathrm{N}_{2} \mathrm{O}\right)$, Hidrofloro Karbonlar (HFCs), Perfloro Karbonlar (PFCs) ve Sülfür Heksaflorit $\left(\mathrm{SF}_{6}\right)$ 'dir. $\mathrm{Bu}$ gazlar arasında en tehlikeli olan Sülfür Heksaflorit ve en az tehlikeli olanı ise Karbon Dioksit olarak tanımlanmaktadır. Ancak atmosferdeki miktarı açısından $\mathrm{CO}_{2}$ diğer gazlara oranla çok yüksek seviyede olmasından dolayı çevreye verdiği zarar açısından en tehlikeli gaz $\mathrm{CO}_{2}$ 'dir [2].

2015 Aralığında gerçekleştirilen COP 21'de ise BMIDÇS'ye taraf olan 197 ülkenin hepsinin küresel iklim değişikliğini 2100 senesine kadar sanayi öncesi döneme göre $2{ }^{\circ} \mathrm{C}$ 'nin altında ve mümkünse $1.5^{\circ} \mathrm{C}$ ile sinırlanmasını öngören Paris Anlaşması imzalanmıştır. 2020'de işlerlik kazanacak olan bu yeni anlaşmayı günümüze kadar 185 ülkenin onayladığı görülmektedir [3].

Ülkemizde sera gazı emisyonlarına yönelik adımlar 17 Mayıs 2014 tarihli Çevre ve Şehircilik Bakanlığı tarafından hazırlanan "Sera Gazı Emisyonlarının Takibi (SGET) hakkında Yönetmelik" ile atılmıştır [4].

Ancak, yürürlükte olan mevzuatta, atıksu arıtma tesisleriyle ilgili bilgi verilmemiş olup, ilgili mevzuatın Ek1 listesinde üretim yapan tesislere yönelik bilgiler verilmiştir. Mevzuat Ek-2 listesinde yer alan, sera gazı emisyonu kaynağı olarak yer verilmemiştir. Atıksu arıtma süreçlerinde üretilen temel sera gazları, karbondioksit $\left(\mathrm{CO}_{2}\right)$, metan $\left(\mathrm{CH}_{4}\right)$ ve nitröz oksit $\left(\mathrm{NO}_{2}\right)^{\prime}$ tir. Karbondioksit üretimi arıtma prosesi ve elektrik tüketimi olmak üzere iki şekilde meydana gelir. Atıksudaki organik bileşiklerin anaerobik ortamda bozunmasıyla ve aerobik arıtma çamurlarının bertarafi esnasında $\mathrm{CH}_{4}$ meydana gelir. $\mathrm{CH}_{4}$ üretimi, birincil olarak atıksudaki bozunabilir organik madde miktarına, sıcaklık ve arıtma sistemi türüne bağlıdır. Atıksu arıtma tesislerinde üretilen metan, giriş KOI değerinin yaklaşık $\% 0,85$ 'ine denk gelmektedir [5]. Biyolojik atıksu arıtımında nitrifikasyon ve denitrifikasyon prosesleri sonucu $\mathrm{N}_{2} \mathrm{O}$ emisyonları oluşabilir. Atıksu arıtma tesislerinin deşarjından kaynaklanan $\mathrm{N}_{2} \mathrm{O}$ emisyonları azot giderimine bağlı olarak gerçekleşen nitrifikasyon - denitrifikasyon bakterileri tarafından nitrojene dönüştürülmesinden kaynaklı olabilmektedir [6].

$\mathrm{Bu}$ çalışmada, atıksu arıtma tesislerinin ECAM (The Energy Performance and Carbon Emissions Assessment and Monitoring) modeli kullanılarak, meydana gelen sera gazı emisyonlarının $(\mathrm{CO} 2, \mathrm{CH} 4, \mathrm{~N} 2 \mathrm{O})$ miktarı ve kaynaklandığı yerin tespiti yapılarak, bu emisyonların oluşmasında etkili olan koşulların saptanması ve proses işletimindeki etkileri ile sera gazı emisyon optimizasyonu ve minimizasyonunun yapılması amaçlanmıştır. Bu çalışma kapsamında, Muratlı Organize Sanayi Bölgesi (Muratlı OSB)'ne ait evsel ve endüstriyel atıksuların arıııldığı arıtma tesisi seçilmiştir.

\section{Materyal ve metot}

\subsection{Muratlı organize sanayi bölgesi ve atısu arttma tesisi'nin tanitımı}

Çalışma alanı olan Muratlı OSB'ye ait kurulu atıksu arıtma tesisi, Tekirdağ il merkezinden $23 \mathrm{~km}$ uzaklıkta bulunan Muratlı ilçesinde yer almaktadır [7] (Şekil 1)

Organize Sanayi Bölgesi'ne ait evsel ve endüstriyel atıksuların arıtıldığı $25.000 \mathrm{~m}^{3} /$ gün kurulu debi kapasitesine sahip merkezi arıtma tesisinin mevcut durumda günlük yaklaşık $5000 \mathrm{~m}^{3} /$ gün atıksu debisi bulunmaktadır. Muratı OSB'de toplamda 27 tane faaliyette olan firma olup, Muratl OSB Atıksu Arıtma Tesisi'ne atıksu hattı bulunan 18 firma bulunmaktadır. Tesisin 2018 - 2019 (Eylül) yılları arasındaki işletme döneminde atıksu arıtma tesisine toplamda 3 firma bağlı bulunurken, 2019 yılı Eylül ayı itibariyle ikinci altyapıların tamamlanmasıyla 15 firma daha eklenerek toplam 18 firmanın atıksu hattı Muratlı OSB Atıksu Arıtma Tesisine bağlanmıştır.

Kurulu endüstrilerin sektörel dağılımına bakıldığında; tekstil, kâğıtt-karton geri dönüşüm, yağ, makine, kimya, gıda, otomotiv, kauçuk sektörleri yer almaktadır.

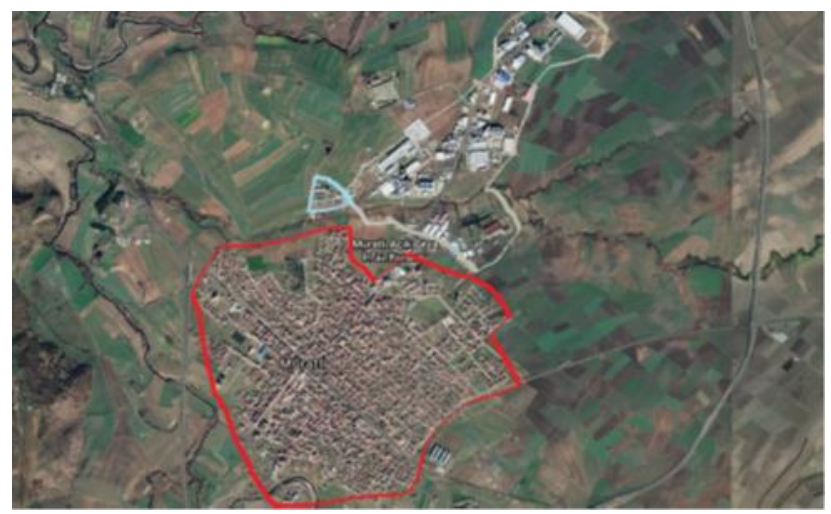

Şekil 1. Muratlı organize sanayi bölgesi

Firmalardan gelen atıksu, kaba ızgaralardan geçtikten sonra giriş terfi pompalarıyla terfi kazandırılarak fiziksel arıtma ön arıtma işlemlerine tabi tutulmaktadır. Fiziksel arıtmadan çıkan atıksu, dengeleme terfi pompaları yardımıyla biyolojik arıtma ünitesine iletilmektedir. Biyolojik arıtma ünitesinin ilk aşaması olan biyofosfor havuzunda, anaerobik ortam koşullarında anaerobik bakteriler tarafindan atıksu içerisindeki yağ asitlerinin tüketimiyle, bünyelerinde bulunan polifosfatı ortofosfat olarak atıksu salınımı gerçekleştirerek fosfor miktarı arttırılır. Daha sonra anaerobik biyofosfor havuzundaki atıksu, havalandırma havuzlarına iletilerek aerobik ve anoksik ortam koşullarında salınmış fosforun aşırı depolanmasını sağlayarak fosfor giderimi gerçekleştirilir.

Havalandırma havuzları birden fazla proses işletimine göre tasarlanmış olup, $\% 50$ aktif çamur, $\% 50 \mathrm{~A}^{2} \mathrm{O}$ prosesine göre işletimi sağlanmaktadır. Havalandırma havuzlarında, 0.4-1.6 mg/L çözünmüş oksijen varlığında nitrifikasyon ve denitrifikasyon işlemleri gerçekleştirilerek karbon, azot ve fosfor giderimi yapılmaktadır. Havalandırma havuzlarından çıkan atıksu, biyolojik çöktürme havuzlarına gelerek burada çöktürülerek çamur depolama havuzlarına ve çamur geri 
devir istasyonuna iletilmektedir. Biyolojik çöktürme havuzlarında savaklardan çıkan arıtılmış atıksu kimyasal arıtma ünitesine iletilmektedir. Kimyasal arıtma ünitesinde hızlı ve yavaş karıştırıcı ünitelerinde gerekli durumlarda fosfor ve renk giderimi için kimyasal dozaj yapılmaktadır. $\mathrm{Bu}$ üniteden çıkan atıksu, kimyasal çöktürme havuzlarında çöktürülerek savaklardan çıkan atıksu çıkış yapısına iletilerek alıcı ortama (Kurudere) deşarjı sağlanmaktadır. Çamur depolama havuzları 2 adet olup, biyolojik arıtmadan oluşan çamurlar her iki havuzda da toplanabilmektedir. Burada biriktirilen çamurların, dekantörlerde kimyasallar kullanımı ile susuzlaştırılması sağlanarak yaklaşı \%20 kuruluğa sahip çamur keki, kamyon kasasına doldurularak anlaşmalı lisanslı firmalar ile bertarafı sağlanmaktadır (Şekil 2).

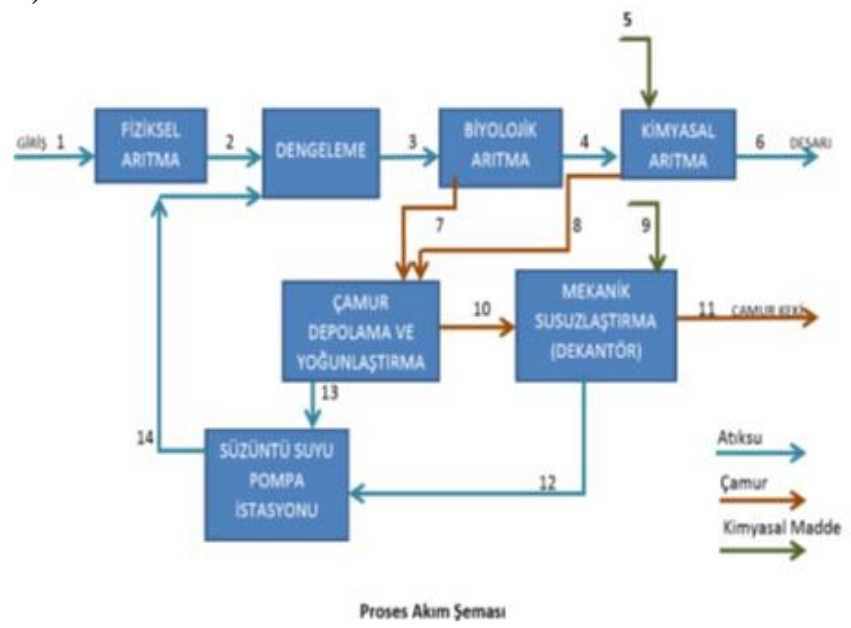

Şekil 2. Muratlı OSB A.A.T. proses akım şeması

\subsection{ECAM modeli}

Dünya çapında 140 ülkede üyesi bulunan Uluslararası $\mathrm{Su}$ Organizasyonu (International Water Association-IWA), günümüzde su ve atıksu ile ilgili problemlere sürdürülebilir çözümler getiren uluslararası bir kuruluştur [8]. IWA'nın alt dalı olan İklim Değişikliği ile Mücadele amaçlı Su ve Atıksu Şirketleri (Water and Wastewater Companies for Climate Mitigation-WaCCliM) organizasyonu tarafindan su ve atıksu yönetiminden kaynaklanan sera gazı emisyonlarının hesaplamaları için ECAM (Enerji Performansı ve Karbon Emisyonları İzleme ve Değerlendirme Aracı) modeli geliştirilmiştir. İnternet üzerinden ücretsiz erişim sağlanabilen ECAM modeli, su ve atıksu alanında karbon emisyonları için saptama ve optimizasyon sağlamaktadır.

Sera gazı emisyonu tahmini için ECAM model yazılımında iki ana değerlendirme yapılmaktadır. Birinci adım olan Faz I aşamasında, sistemin elektrik tüketimi ve sera gazı emisyonu hakkında pasta grafik ve şekiller üzerinde genel bir değerlendirme elde edilmektedir. İkinci adım olan Faz II aşamasında ise atıksu ve çamur yönetimi bölümleri hakkında detaylı bir değerlendirme yapılmaktadır. Yazılım üzerinde atıksu arıtma tesisi 4 adımda incelenmektedir. Bunlar; 1) Toplama, 2) Arıtma, 3) Deşarj/Geri Kullanım, 4) Bertaraf/Geri Kullanım'dır.

Bu çalışma kapsamında; Faz-1'de Muratlı OSB A.A.T. ne bağlı bulunan firmaların herhangi bir terfilendirme işlemine tabii tutulmadığı ve gelen atıksu kendi cazibesiyle tesise giriş yaptığ 1 için atıksu toplama adımı ihmal edilmiştir. Faz-2'de MOSB'ye yeni bağlanan tesislerin bağlı olduğu terfi istasyonu hesaplamaları ise atıksu arıtma bölümüne dahil edilmiştir.

İkinci adım olan arıtmada; ECAM modeli kentsel atıksu arıtma tesislerine yönelik tasarlandığ 1 için $\mathrm{BOI}_{5}$ parametresi kullanılmıştır. Enerji ve atıksu girdilerinin sağlanması ve arıtma tesisine ait kirlilik parametrelerinden $\mathrm{BOI}_{5}$ yük verilerinin girilmesiyle $\mathrm{BOI}_{5}$ kütle giderimi başına tüketilen enerji miktarı ve elektrik, işletme prosesi ve toplam sera gazı emisyonu hakkında çıktılar elde edilmiştir. Ancak arıtma tesisine ait $\mathrm{BOI}_{5}$ verilerinin mevcut olmadığından dolayı tesisin $\mathrm{BOI}_{5} / \mathrm{KOI}$ oranına üzerinden $\mathrm{KOI}$ verileri üzerinden $\mathrm{BOI}_{5}$ yük verileri hesaplanmıştır.

Üçüncü adım olan deşarj/geri kullanımda ise; deşarj için tüketilen enerji miktarı, deşarj edilen atıksu miktarı, çıkış suyundaki toplam azot ve $\mathrm{BOI}_{5}$ yükü girdileri sonucunda elektrik, toplam sera gazı emisyonu, deşarj edilen ve tekrar kullanılan atıksu için birim $\mathrm{m}^{3}$ başına düşen tüketimler hakkında detaylı bilgiler edinilmiştir. Arıtma tesisinde çıkış suyunun geri kullanımı, dekantörlerin çalışmasında gerekli olan kimyasalın çözelti olarak hazırlanması sırasında kullanılmaktadır.

Dördüncü adım olan çamur yönetiminde; Muratlı OSB A.A.T.'de çamur ünitesi sonucu son ürün olarak oluşan çamur keki, günlük olarak konteynerde toplanarak taşıma şirketine ait kamyon vasitasıyla bertaraf edilmektedir. Çamur yönetimi adımında, çamur bertarafı için tüketilen enerji, atıksu miktarı ve toplam azot ve $\mathrm{BOI}_{5}$ yük girdileri sonucunda bertaraftan kaynaklanan sera gazı emisyonu çıktıları elde edilmiştir.

ECAM Modeline ait girdi ve çıktılar Şekil 3'te özetlenmiştir.
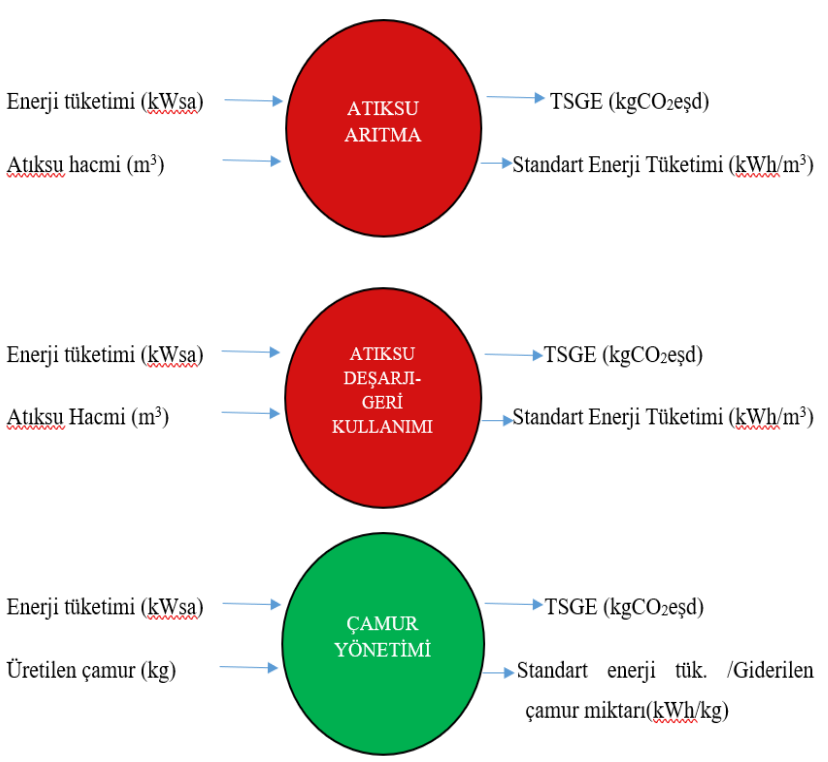

Şekil 3. ECAM modelinde girdi ve çıktılar (TSGE: Toplam Sera Gazı Emisyonu) 


\section{Bulgular ve tartışma}

\subsection{Debi ve atıksu karakteristikleri}

Muratlı OSB Atıksu Arıtma Tesisi için farklı senaryolar üzerinde yaklaşım yapılmıştır. Birinci senaryoya göre veri akışının düzenli olarak sağlandığı 3 aylık zaman dilimi içerisinde, 2019 yılına ait Haziran, Temmuz ve Ağustos ayları için ECAM modeli kullanılarak doğrudan ve dolaylı sera gazı emisyonları tahmin edilmiş ve bu senaryo yaklaşımı Faz-1 olarak adlandııılmıştır. Aylık veriler sisteme girilerek seçilen her bir ay için sera gazı emisyon miktarları hesaplanmıştır. Çalışmada, Temmuz ayına ait verilerin ECAM model üzerinde kullanımına yönelik girdi ve çıktı hesaplamaları verilmiştir.

İkinci senaryoya göre, atıksu altyapı inşaat işlemlerinin tamamlanmasıyla atısu arıtma tesisine 15 firma dahil edilmiştir. Toplamda 18 firmanın atıksuyunu verdiği 2019 yılına ait Aralık ayı üzerinde ECAM modeli uygulanmış ve sonuçların sera gazı emisyonunu ne şekilde etkilediği ve tahmin edilen miktarlar açısından nelerin değiştiği ile ilgili olarak yaklaşım sürdürülmüştür. $\mathrm{Bu}$ senaryoda kullanılan Aralık ayı verileri ve hesaplamaları Faz-2 olarak adlandırılmıştır. Faz-1 aşamasına göre değerlendirildiğginde, en yüksek kirlilik yüklerine Ağustos ayında rastlanılmıştır (Şekil 4). Faz-2 aşaması eklendiğinde, Faz-1 deki aylara göre kıyaslama yapıldığında AKM ile Toplam Azot kirlilik yüklerinde ve atıksu miktarında Aralık ayının en yüksek olduğu görülmektedir (Şekil 4).

\subsection{ECAM modeli sonuçları}

ECAM Model uygulamasında Haziran, Temmuz, Ağustos ve Aralık aylarındaki sera gazı emisyon tahmini yapılmıştır. Elektrik tüketiminin aylara göre dağılımına göre, 224.829,4 kWsa ile Aralık ayında en yüksek tüketim gerçekleşmiş; en düşük elektrik tüketiminin olduğu ay ise 174.691,4 ile Haziran ayı olmuştur (Şekil 5). Tahmin edilen toplam sera gazı emisyonu (TSGE) miktarlarına bakıldığında, $226.573 \mathrm{kgCO}_{2}$ eşd. ile Aralık ayında en yüksek değer ve en düşük toplam sera gazı emisyonuna ise $176.707 \mathrm{kgCO}_{2}$ eşd. ile Haziran ayında hesaplanmıştır (Şekil $5)$.

Çalışma alanına ait sera gazı emisyonu miktarları, ECAM program metoduyla bölümlere ayrılarak, bu bölümlerde oluşan direkt ve dolaylı sera gazı emisyonu miktarları hesaplanarak Tablo 1'de verilmiştir. Enerji tüketiminden oluşan sera gazı emisyonları dolaylı sera gazı emisyonları olarak adlandırılmaktadır. Arıtma tesisi işletme prosesi sonucu oluşanlar ise direkt sera gazı emisyonları olarak adlandırılmaktadır. Toplam sera gazı emisyonları, dolaylı ve direkt sera gazı emisyonlarının toplamına eşittir.

Faz-1'de Muratlı OSB A.A.T. sera gazı emisyonu değerlendirmesi yapılmış ve buna göre 2019 yılı yaz ayları kapsamında Haziran, Temmuz ve Ağustos aylarında tahmin edilen en yüksek emisyon miktarı, Temmuz ayına ait olduğu görülmüştür (Tablo 1). Faz-2'de altyapı hizmetlerinin tamamlanmasıyla atıksu arıtma tesisine firmalar bağlanmış olup, artan yük ve debi ile program ikinci kez çalıştırılmıştır. 2019 Aralık ayına ait veriler kullanılarak karşılaştırma yapılmıştır.

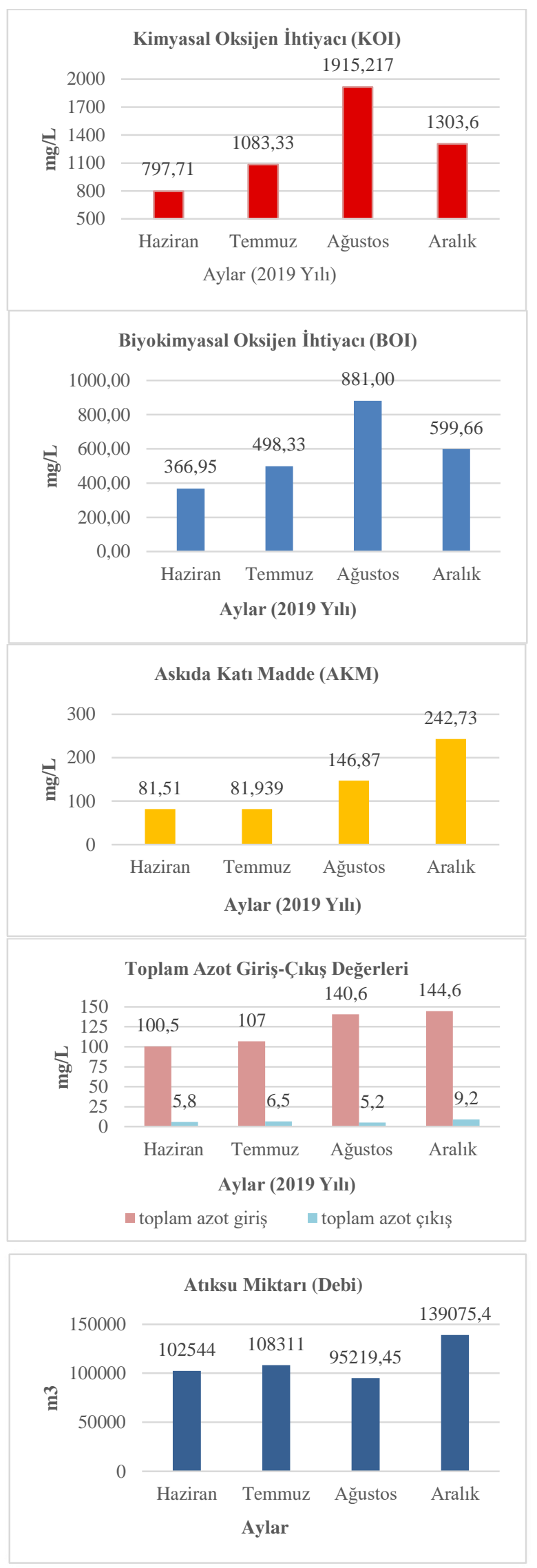

Şekil 4. Aylara göre tesis işletme verileri 

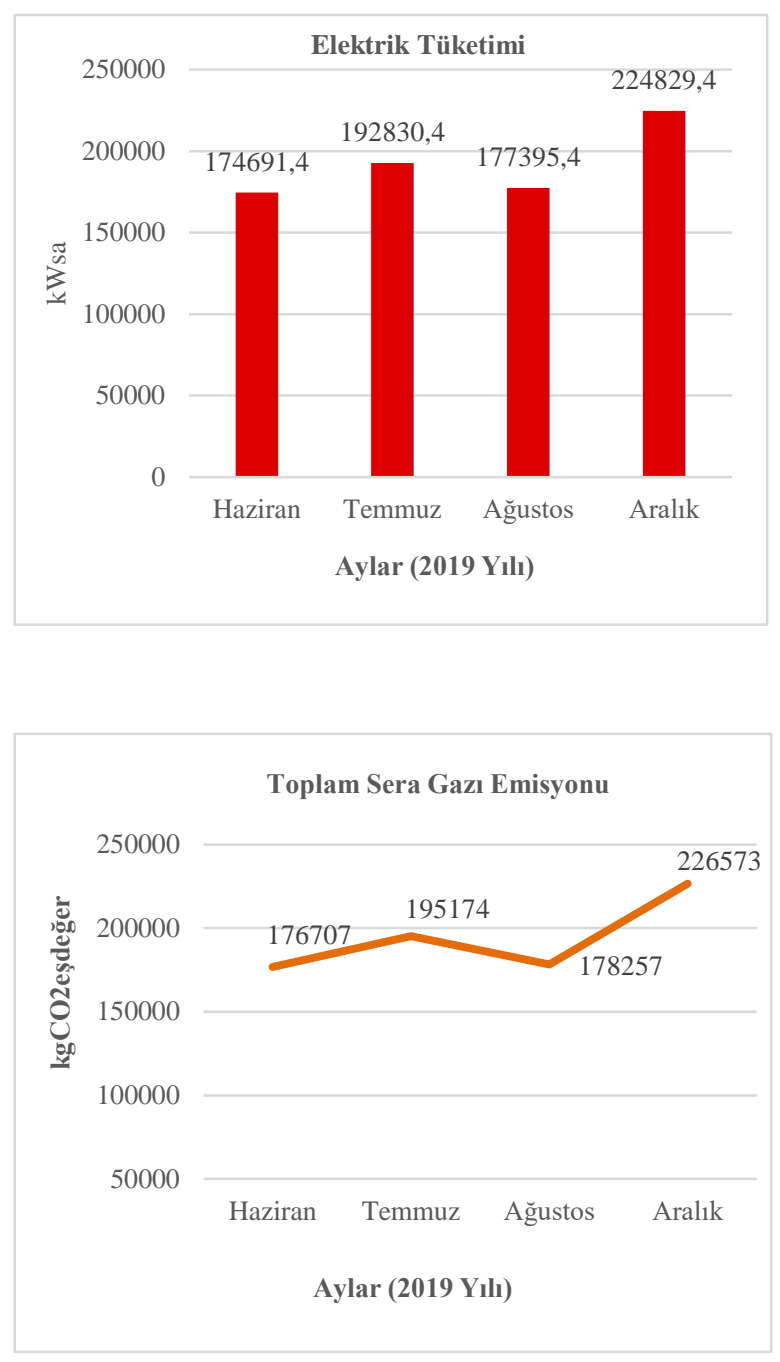

Şekil 5. 2019 yılına ait aylara göre elektrik tüketimi ve toplam sera gazı emisyonu dağılımı

Tablo 1. Aylara göre direkt ve dolaylı sera gazı emisyonlarının (SGE) tahmini (Birim: $\mathrm{kgCO}_{2}$ eşd.)

\begin{tabular}{cccccc}
\hline $\begin{array}{c}\text { ECAM tool } \\
\text { hesaplama } \\
\text { adımları }\end{array}$ & SGE türü & $\begin{array}{c}\text { Haziran } \\
2019\end{array}$ & $\begin{array}{c}\text { FAZ-1 } \\
\text { Temmuz } \\
2019\end{array}$ & $\begin{array}{c}\text { Ağustos } \\
2019\end{array}$ & $\begin{array}{c}\text { FAZ-2 } \\
\text { Aralı } \\
2019\end{array}$ \\
\hline \multirow{2}{*}{ Arıtma } & Dolaylı SGE & 142.913 & 157.577 & 145.254 & 185.797 \\
& Direkt SGE & 1.674 & 1.769 & 1.506 & 2.271 \\
Deşarj/Geri & Dolaylı SGE & 8.310 & 9.349 & 8.310 & 8.830 \\
Kullanım & Direkt SGE & 6.488 & 7.326 & 6.162 & 11.586 \\
\multirow{2}{\text{Çamur}}{} & Dolaylı SGE & 8.310 & 9.349 & 8.310 & 8.830 \\
Yönetimi & Direkt SGE & 8.714 & 9.804 & 8.714 & 9.259 \\
& Toplam SGE & 176.707 & 195.174 & 178.257 & 226.573 \\
\hline
\end{tabular}

Örnek hesaplama olarak, Temmuz ayına ait ECAM modelleme metoduyla yapılan hesaplamalar aşağıda verilmiştir.

\subsection{FAZ-1 temmuz ayı genel sera gazı emisyonu değerlendirmesi (A aşaması)}

Yaz ayları verilerinin kullanıldığı Faz-1 aşamasına göre, atıksu arıtma tesisi için genel sera gazı değerlendirmesinde; en yüksek sera gazı emisyonu $195,174 \mathrm{kgCO}_{2}$ eq ile Temmuz 2019 ay1 olduğu görülmüştür. Temmuz ayı değerlendirmesinde; direkt emisyon kaynağ olan $\mathrm{CH}_{4}$ miktarı \%2.9 oranında $5,568 \mathrm{kgCO}_{2} \mathrm{eq}$; diğer bir direkt emisyon kaynağı $\mathrm{N}_{2} \mathrm{O}$ miktarı \%1.9 oranında 3,695 kgCO2eq; dolaylı emisyon kaynağı elektrik tüketiminden oluşan sera gazı emisyonu \%90.3 oranında 176,275 kgCO2eq; taşımadan kaynaklı oluşan $\mathrm{CO} 2$ miktarı \%4.9 oranında $9,635 \mathrm{kgCO}_{2}$ eq ve toplam sera gazı emisyonu $195,174 \mathrm{kgCO}_{2}$ eq olarak hesaplanmıştır (Şekil 6).

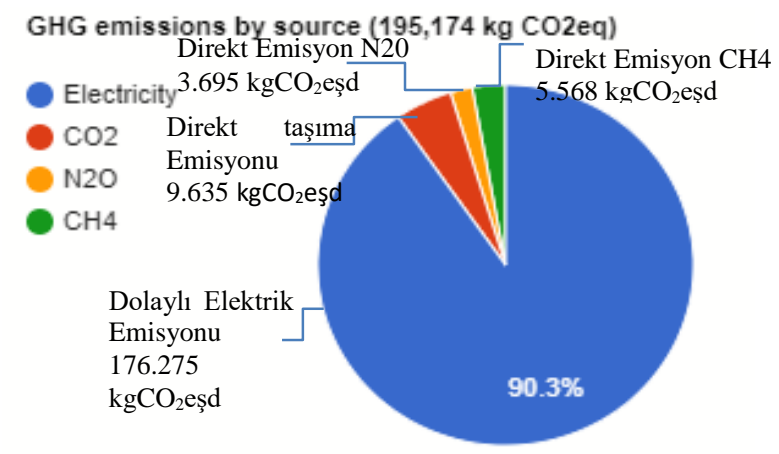

Şekil 6. Temmuz ayı direkt $\left(\mathrm{N}_{2} \mathrm{O}\right.$ ve $\left.\mathrm{CH}_{4}\right)$ ve dolaylı (elektrik ve taşımadan kaynaklı $\mathrm{CO}_{2}$ ) emisyon miktar dağılımı

\subsection{FAZ-1 temmuz ayl sera gazı emisyonu değerlendirmesi (B aşaması)}

\subsubsection{Arıtma bölümünden kaynaklanan sera gazı emisyonlart}

B aşaması atıksu adımı için gerekli girdiler Tablo 2'de verilmiştir:

Tablo 2. ECAM modelinde atıksu bölümü girdi verileri

\begin{tabular}{ccc}
\hline $\begin{array}{c}\text { Arıtma } \\
\text { Girdiler }\end{array}$ & Temmuz & Birim \\
\hline $\begin{array}{c}\text { Şebekeden tüketilen enerji } \\
\text { (wwt_nrg_cons) }\end{array}$ & 182.030 & $\mathrm{kWsa}$ \\
Hizmet edilen nüfus (wwt_serv_pop) & 17.470 & $\mathrm{kişi}$ \\
Arıtılmış atıksu hacmi (wwt_vol_trea) & 108.311 & $\mathrm{~m} 3$ \\
CH4 emisyon faktörü (wwt_ch4_efac) & 0 & $\mathrm{kgCH}_{4} / \mathrm{kgBOI}$ \\
BOI giriş yükü (wwt_bod_infl) & 53.975 & $\mathrm{~kg}$ \\
BOI çıkış yükü (wwt_bod_effl) & 2.721 & $\mathrm{~kg}$ \\
Çamurda giderilen BOI (wwt_bod_slud) & 35.084 & $\mathrm{~kg}$ \\
Giderilen BOI kütlesi & 51.254 & $\mathrm{~kg}$ \\
\hline
\end{tabular}

B aşaması atıksu bölümünde elde edilen çıktılar ve toplam sera gazı emisyonu Temmuz ayı için Tablo 3'te verilmiştir: 
Tablo 3. ECAM modelinde atıksu bölümü çıktı verileri

\begin{tabular}{ccc}
\hline Çıktılar -TSGE & Temmuz & Birim \\
\hline $\begin{array}{c}\text { Elektrik Emisyonu } \\
\text { (wwt_KPI_GHG_elec) }\end{array}$ & 157.577 & $\mathrm{kgCO}_{2}$ eşd/ay \\
Arıtma Prosesi & & \\
$\begin{array}{c}\text { Emisyonu } \\
\text { (wwt_KPI_GHG_tre) } \\
\text { Toplam Arıtma Sera } \\
\text { Gazı Emisyonu } \\
\text { (wwt_KPI_GHG) }\end{array}$ & 1.769 & $\mathrm{kgCO}_{2}$ eşd/ay \\
\hline
\end{tabular}

$\mathrm{Bu}$ çalışmada, ECAM modeli üzerinde her bir ülkeye göre elektrik şebekesinden gelen elektrik tüketim değerleri için "Elektrik emisyon faktörü" belirlenmiştir. Türkiye için elektrik emisyon faktörü $0,87 \mathrm{~kg}_{\mathrm{CO} 2} / \mathrm{kWsa}^{\prime}$ tir [9]. Buna göre, Temmuz ayına ait elektrik tüketiminden kaynaklanan dolaylı sera gazı emisyon hesapları aşağıda yer almaktadır:

\subsubsection{Dolayli sera gazl emisyonu hesapları - aritma prosesi-elektrik emisyonu}

Temmuz ayı arıtma prosesinde elektrikten kaynaklanan dolaylı sera gazı emisyonu Denklem (1)'den hesaplanarak $157.577 \mathrm{kgCO}_{2}$ eşdeğer olarak tahmin edilmiştir.

$$
\begin{gathered}
\text { Elektrik emisyonu }=\text { Şebekeden tüketilen enerji } \\
\text { x Elektrik emisyon faktörü }
\end{gathered}
$$

\subsubsection{Direkt sera gazı emisyonu hesaplarl - aritma prosesi $-\mathrm{CH}_{4}-\mathrm{N}_{2} \mathrm{O}$ emisyonlarl}

Arıtma prosesinde oluşan $\mathrm{CH}_{4}$ emisyonu hesabı, biyolojik atıksu arıtma proseslerindeki $\mathrm{CH}_{4}$ emisyon faktörü, arıtma türüne göre değişkenlik göstermektedir. Tablo 4 e göre bu tesis için aktif çamur - iyi yönetilmiş seçeneği seçildiğinden dolayı $0 \mathrm{kgCH}_{4} / \mathrm{kgBOI}$ olarak alınmıştır.

Tablo 4. IPCC 2006'ya göre metan emisyon faktörleri [10]

\begin{tabular}{ccc}
\hline Arıtma türü & $\begin{array}{c}\text { Metan } \\
\text { Düzeltme } \\
\text { Faktörü } \\
\text { (MCF) }\end{array}$ & $\begin{array}{c}\text { Emisyon } \\
\text { Faktörü } \\
\text { (EF) }\end{array}$ \\
\hline $\begin{array}{c}\text { Merkezi aerobik arıtma tesisi (iyi } \\
\text { yönetilen) }\end{array}$ & 0 & 0 \\
$\begin{array}{c}\text { Merkezi aerobik arıtma tesisi, küçük } \\
\text { gözenekli havalı bölgeler } \\
\text { Merkezi aerobik arıtma tesisi, bazı havalı } \\
\text { bölgeler ile }\end{array}$ & 0.1 & 0.06 \\
$\quad \begin{array}{c}\text { Merkezi aerobik arıtma tesisi (iyi } \\
\text { yönetilmeyen) }\end{array}$ & 0.2 & 0.12 \\
\hline
\end{tabular}

Metan emisyonu hesabında, iyi yönetilen tesisler için metan emisyon faktörü $0 \quad \mathrm{kgCH}_{4} / \mathrm{kgBOI}$; metanın karbondioksit eşdeğeri olarak 34 alındığında, ECAM model denkleminde kullanılarak $0 \mathrm{kgCO}_{2}$ eşd olarak hesaplanmıştır.

Arıtma prosesinde oluşan $\mathrm{N}_{2} \mathrm{O}$ emisyonu hesabi; arıtmadan kaynaklanan nitröz oksit emisyonu hesabında, $\mathrm{N}_{2} \mathrm{O}$ 'nun karbondioksit eşdeğeri 298 kattır. Yani IPCC 5th
AR (2014/2013) CCF raporu küresel 1sınma potansiyeli tablosuna göre $1 \mathrm{CO}_{2}$ eşdeğeri, $298 \mathrm{~N}_{2} \mathrm{O}$ 'ya eşittir [11].

Model formülasyonunda kullanılarak arıtma prosesinde oluşan nitröz oksit emisyonu $1.769 \mathrm{kgCO}_{2}$ eşd olarak hesaplanmıştır.

Arıtma Prosesinde oluşan sera gazı emisyonu arıtma prosesinden kaynaklanan $\mathrm{CH}_{4}$ emisyonu ve $\mathrm{N}_{2} \mathrm{O}$ emisyonunun toplamına eşittir.

Arıtma prosesi sera gazı emisyonu $=$ Arıtma prosesindeki $\mathrm{CH}_{4}$ emisyonu + Aritma prosesindeki $\mathrm{N}_{2} \mathrm{O}$ emisyonu

Arıtma prosesinde oluşan sera gazı emisyonu Denklem (2) kullanılarak $1.769 \mathrm{kgCO}_{2}$ eşd olarak hesaplanmıştır.

\subsubsection{Arıtmadan kaynaklı toplam sera gazı emisyonu}

Arıtmadan kaynaklı toplam sera gazı emisyonu, arıtma için tüketilen enerjiden kaynaklanan dolaylı sera gazı emisyonu olan elektrik ve aritmadan kaynaklanan $\mathrm{CH}_{4}$ ve $\mathrm{N}_{2} \mathrm{O}$ emisyonlarının toplamına eşittir. Tablo 5'te Temmuz ayına ait enerji performansı ve hizmet düzeyi faktörleri çıktıları verilmiştir:

Toplam Sera Gazı Emisyonu = Dolaylı sera gazı emisyonu (Elektrik)+ Direkt sera gazı emisyonu $\left(\mathrm{CH}_{4}+\mathrm{N}_{2} \mathrm{O}\right)$

Denklem (3) ile arıtma prosesinden kaynaklanan toplam sera gazı emisyonu $159.346 \quad \mathrm{kgCO}_{2}$ eşd olarak hesaplanmıştır.

Tablo 5. Temmuz ayı enerji performansı ve hizmet düzeyi faktör çıktıları - arıtma prosesi

\begin{tabular}{ccc}
\hline $\begin{array}{c}\text { Çıktılar -Enerji } \\
\text { Performansı ve Hizmet } \\
\text { Düzeyi Faktörleri }\end{array}$ & Temmuz & Birim \\
\hline $\begin{array}{c}\text { Arıtılmış atıksu } \\
\text { başına enerji tüketimi } \\
\text { (wwt_KPI_nrg_per_m3) }\end{array}$ & 1.68 & $\mathrm{kWsa} / \mathrm{m}^{3}$ \\
$\begin{array}{c}\text { BOI5 kütle giderimi } \\
\text { başına enerji tüketimi } \\
\text { (wwt_KPI_nrg_per_kg) }\end{array}$ & 3.55 & $\mathrm{kWsa/kg}$ \\
$\begin{array}{c}\text { Günde kişi başına } \\
\text { arıtılmış atıksu } \\
\text { (wwt_SL_vol_pday) }\end{array}$ & & \\
\hline
\end{tabular}

\subsubsection{Deşarj/ geri kullanım bölümünden kaynaklanan sera gazı emisyonu tahmini}

Muratlı OSB A.A.T. için ECAM programında deşarj/geri kullanım bölümüne ait Temmuz ayı girdileri Tablo 6'da verilmiştir:

Deşarj/Geri kullanım bölümüne ait sera gazı emisyonu çıktıları Tablo 7'de gösterilmiştir:

Tablo 8'de deşarj/geri kullanım bölümüne ait enerji performansı ve hizmet düzeyi faktörleri çıktıları verilmiştir: 
Tablo 6. ECAM model deşarj/geri kullanım bölümü girdi verileri

\begin{tabular}{ccc}
\hline Deşarj & Temmuz & Birim \\
Girdiler & & \\
\hline $\begin{array}{c}\text { Şebekeden tüketilen enerji } \\
\text { (wwd_nrg_cons) } \\
\text { Alı1 ortama deşarjedilen } \\
\text { atıksu hacmi (wwd_vol_disc) }\end{array}$ & 10.800 & $\mathrm{kWsa}$ \\
$\begin{array}{c}\text { Çıkış BOI yükü } \\
\text { (wwd_bod_effl) }\end{array}$ & 2.721 & $\mathrm{~kg}$ \\
$\begin{array}{c}\text { Çıkıştaki toplam azot } \\
\text { konsantrasyonu (wwd_n2o_effl) } \\
\text { CH4 emisyon faktörü } \\
\text { (wwd_ch4_efac) }\end{array}$ & 7 & $\mathrm{mg} / \mathrm{L}$ \\
$\begin{array}{c}\text { Geri kullanılan çıkışs suyu } \\
\text { hacmi (wwd_vol_nonp) }\end{array}$ & 0,06 & $\mathrm{kgCH}_{4} / \mathrm{kgBOI}$ \\
\hline
\end{tabular}

Tablo 7. ECAM model deşarj/geri kullanım bölümü çıktı verileri

\begin{tabular}{|c|c|c|}
\hline Çıktılar - TSGE & Temmuz & Birim \\
\hline $\begin{array}{r}\text { Elektrik Emisyonu } \\
\text { (wwd_KPI_GHG_elec) }\end{array}$ & 9.349 & $\mathrm{kgCO}_{2}$ eşd/ay \\
\hline $\begin{array}{c}\text { Deşarj atıksuyu sera gazı } \\
\text { Emisyonu(wwd_KPI_GHG_tre) } \\
\text { Toplam GHG Deşarj/Geri }\end{array}$ & 7.326 & $\mathrm{kgCO}_{2}$ eşd/ay \\
\hline $\begin{array}{l}\text { kullanılan atıksu Emisyonu } \\
\text { (wwd_KPI_GHG) }\end{array}$ & 16.675 & $\mathrm{kgCO}_{2}$ eşd/ay \\
\hline
\end{tabular}

Tablo 8. Temmuz ayı enerji performansı ve hizmet düzeyi faktör çıktıları -deşarj bölümü

\begin{tabular}{ccc}
\hline $\begin{array}{c}\text { Çıktılar - Enerji Performansı ve } \\
\text { Hizmet düzeyi faktörleri }\end{array}$ & Temmuz & Birim \\
\hline $\begin{array}{c}\text { Deşarj edilen atıksu başına } \\
\text { enerji tüketimi } \\
\text { (wwd_KPI_nrg_per_m3) } \\
\begin{array}{c}\text { Toplam deşarj/geri kullanılan } \\
\text { atıksu sera gazı emisyonu } \\
\text { (wwd_total_m3) }\end{array}\end{array}$ & 0,1 & $\mathrm{kWsa} / \mathrm{m}^{3}$ \\
\hline
\end{tabular}

\subsubsection{Dolayli sera gazı emisyonları - atıksu} deşarj/geri kullanım - elektrik emisyonu

Atıksu deşarj/Geri kullanım bölümünden kaynaklanan dolaylı sera gazı emisyonları Denklem (4) kullanılarak 9.349 $\mathrm{kgCO}_{2}$ eşd olarak tahmin edilmiştir.

\section{Elektrik Emisyonu $=$ Şebekeden tüketilen enerji $\mathrm{x}$ Elektrik emisyon faktörü}

\subsubsection{Direkt sera gazı emisyon hesapları - atıksu deşarj/geri kullanımı prosesi - $\mathrm{CH}_{4}-\mathrm{N}_{2} \mathrm{O}$ emisyonlart}

Atıksu deşarjı/geri kullanımdan kaynaklanan $\mathrm{N}_{2} \mathrm{O}$ emisyon hesabında, $\mathrm{N}_{2} \mathrm{O}$ 'in $\mathrm{CO}_{2}$ eşdeğeri 298 olduğundan model denklem hesaplaması sonucu $1.775 \mathrm{kgCO}_{2}$ eşdeğer $\mathrm{N}_{2} \mathrm{O}$ emisyonu oluştuğu hesaplanmıştır.

Atıksu deşarj1/geri kullanımdan kaynaklanan $\mathrm{CH} 4$ emisyon hesabında, $\mathrm{CH}_{4}$ 'ün $\mathrm{CO}_{2}$ eşdeğeri 34 olarak alındığında, model denklemi sonucunda $5.551 \mathrm{kgCO}_{2}$ eşd emisyon oluştuğu tahmin edilmiştir.

Toplam atıksu deşarjından kaynaklanan direkt sera gazı emisyonları, atıksu deşarjı/geri kullanımından kaynaklanan
$\mathrm{N}_{2} \mathrm{O}$ ve $\mathrm{CH}_{4}$ emisyonlarının toplamına eşit olduğundan dolayı $7.326 \mathrm{kgCO}_{2}$ eşd olarak tahmin edilmiştir.

\subsubsection{Atıksu deşarjı/geri kullanımdan kaynaklanan toplam sera gazı emisyonu}

2019 yılı Temmuz ayında atıksu deșarjı/geri kullanımdan meydana gelen sera gazı emisyonları, bu bölüm için kullanılan elektrik tüketiminden oluşan emisyonlar ve $\mathrm{N}_{2} \mathrm{O}$, $\mathrm{CH}_{4}$ emisyonlarının toplamına eşittir.

Toplam Sera Gazı Emisyonu =Dolaylı sera gazı emisyonu (Elektrik) + Direkt sera gazı emisyonu (5) (Deşarj/Geri kullanımdan kaynaklanan toplam emisyon)

Denklem (5) ile $16.675 \mathrm{kgCO}_{2}$ eşd atıksu deşarj/geri kullanım bölümünden kaynaklanan toplam sera gazı emisyonu hesaplanmıştır.

\subsection{3 Çamur yönetiminden kaynaklanan sera gazı emisyon tahmini}

Çamur yönetimi bölümünde çamurun bertaraf edilmesi için kullanılan veriler “Tablo 9'da verilmiştir:

Tablo 9. ECAM model çamur yönetimi bölümü girdi verileri

\begin{tabular}{ccc}
\hline Bertaraf-Girdiler & Temmuz & Birim \\
\hline $\begin{array}{c}\text { Sebekeden } \\
\text { tüketilen enerji } \\
\text { (fsr_nrg_cons) } \\
\begin{array}{c}\text { Yakıt türü } \\
\text { (fsr_trck_typ) } \\
\text { Tüketilen yakıt } \\
\text { miktarı }\end{array}\end{array}$ & 10.800 & $\mathrm{kWsa}$ \\
(fsr_vol_trck) & Dizel & \\
\hline
\end{tabular}

Temmuz ayına ait çamur yönetimi bölümünde tahmin edilen sera gazı emisyon miktarları Tablo 10'da verilmiştir:

Tablo 10. ECAM model çamur yönetimi bölümü çıktı verileri

\begin{tabular}{ccc}
\hline Çıktılar - TSGE & Temmuz & Birim \\
\hline $\begin{array}{c}\text { Elektrik emisyonu } \\
\text { (fsr_KPI_GHG_elec) }\end{array}$ & 9.349 & $\mathrm{kgCO}_{2}$ eşd/ay \\
$\begin{array}{c}\text { Taşıma emisyonu } \\
\text { (fsr_KPI_GHG_trck) } \\
\text { Toplam çamur bertarafi } \\
\text { sera gazı emisyonu } \\
\text { (fsr_KPI_GHG) }\end{array}$ & 9.804 & $\mathrm{kgCO}_{2}$ eşd/ay \\
\hline
\end{tabular}

3.4.3.1 Dolayll sera gazı emisyonlarl-bertaraf-elektrik emisyonu

$\mathrm{Bu}$ aşamada meydana gelen dolaylı sera gazı emisyonları, aylık şebekeden tüketilen enerji ile Türkiye için belirlenen elektrik emisyon faktörünün çarpımı sonucunda elde edilen değerlerdir.

Denklem (6) ile Temmuz ayında $9.349 \quad \mathrm{kgCO}_{2}$ eşd bertaraf bölümünden kaynaklı dolaylı sera gazı emisyonları tahmin edilmiştir.

Elektrik emisyonu $=$ Çamur ünitesinde tüketilen enerji $\mathrm{x}$ Elektrik emisyon faktörü 


\subsubsection{Direkt sera gazı emisyonu hesaplart- taşıma emisyonlarl}

ECAM modelinde 3 tipte yakıt türü seçeneği bulunmaktadır. Çalışmada, bertaraf için kullanılan taşıtlarda kullanılan yakıt türü dizel tipidir.

Tablo 11. IPCC, (2006) yakıt türü tablosuna göre [12]; Dizel yakıt türü için;

\begin{tabular}{cc}
\hline $\mathrm{CO}_{2}$ emisyon faktörü $\left(\mathrm{EFCO}_{2}\right)$ & $74.100 \mathrm{kgCO}_{2} / \mathrm{TJ}$ \\
\hline Net kalorifik değeri (fuel NCV) & $43 \mathrm{TJ} / \mathrm{Gg}$ \\
Yakıt yoğunluğu (fuel.FD) & $0.84 \mathrm{~kg} / \mathrm{L}$ \\
Araçlar için $\mathrm{N}_{2} \mathrm{O}$ emisyon faktörü & $3.9 \mathrm{~kg}_{\mathrm{N} 2 \mathrm{O}} / \mathrm{TJ}$ \\
(fuel.EFN2O.vehicles) & $3.9 \mathrm{~kg}_{\mathrm{CH} 4} / \mathrm{TJ}$ \\
Araçlar için $\mathrm{CH}_{4}$ emisyon faktörü & $298 \mathrm{kgCO}_{2}$ eşdeğer/ \\
(fuel.EFCH4.vehicles) & $\mathrm{kgN}_{2} \mathrm{O}$ \\
Nitröz oksit $\mathrm{CO}_{2}$ eşdeğeri & $34 \mathrm{kgCO}_{2}$ eşdeğer/ \\
Metan $\mathrm{CO}_{2}$ eşdeğeri & $3.6 \mathrm{mgCH}_{4}$ \\
\hline
\end{tabular}

Taşımadan kaynaklı $\mathrm{CO}_{2}$ emisyonu, Tablo 11 'de verilen dönüşüm katsayıları kullanılarak yakıt miktarı ile $\mathrm{CO}_{2}$ emisyon faktörü çarpımı sonucu $9.635 \mathrm{kgCO}_{2}$ eşd olarak bulunmuştur. Tablo 11'de verilen dönüşüm katsayıları kullanılarak ECAM model denklemlerinde sirasiyla taşımadan kaynaklanan $\mathrm{N}_{2} \mathrm{O}$ ve $\mathrm{CH}_{4}$ emisyonu; 151,1 $\mathrm{kgCO}_{2}$ eşd ve $17,24 \mathrm{kgCO}_{2}$ eşd olarak tahmin edilmiştir.

Taşımadan kaynaklanan toplam sera gazı emisyonu, $\mathrm{CO}_{2}, \mathrm{~N}_{2} \mathrm{O}$ ve $\mathrm{CH}_{4}$ emisyonlarının toplamına eşit olduğundan $9.804 \mathrm{kgCO}_{2}$ eşd olarak bulunmuştur.

\subsubsection{3 Çamur yönetiminden kaynaklanan toplam sera gazı emisyonu}

Denklem (7) ile bertaraf bölümünden Temmuz ayında $19.153 \mathrm{kgCO}_{2}$ eşd toplam sera gazı emisyonu oluştuğu tahmin edilmiştir.

Toplam sera gazı emisyonu $=$ Dolaylı sera gaz 1 emisyonu ( elektrik ) + Direkt sera gazı emisyonu (taşıma kaynaklı toplam emisyon)

\section{Tartışma}

Literatürde benzer çalışmalar incelendiğinde, Fighir, Teodosiu, Fiore (2019)'da yaptıkları bir çalışmada, Kentsel Atıksu Arıtma Tesislerinden kaynaklanan sera gazı emisyonu değerlendirmesinde ECAM programını kullanarak 4 farklı tesis incelenmişlerdir. Bu tesislerden ikisi İtalya'da, diğer ikisi ise Romanya'da bulunmaktadır. Yapılan çalışmada, tesislerin toplam sera gazı emisyon miktarları A (İtalya-1) tesisinde $25,41 \mathrm{kgCO}_{2} /$ y1 $1 /$ nüfus.; B (İtalya-2) tesisinde $26,81 \mathrm{kgCO}_{2} / \mathrm{yl}_{1} /$ nüfus.; $\mathrm{C}$ (Romanya-1) tesisinde $64,32 \mathrm{kgCO}_{2} / \mathrm{yl} 1 /$ nüfus ve $\mathrm{D}$ (Romanya-2) tesisinde 68,36 $\mathrm{kgCO}_{2} / \mathrm{y} 1 /$ nüfus olarak tahmin edilmiştir. Sera gazı emisyon miktarlarına bakıldığında ülkelerin elektrik emisyon faktörünün düşük olduğu İtalya'da sera gazı emisyon miktarları da Romanya'daki kentsel atıksu arıtma tesislerine göre daha düşük olduğu görülmüştür [13]. Bu çalışma ile kıyaslandığında, elektrik emisyon faktörü bakımından İtalya ve Romanya ülkeleri arasında kalan Türkiye için elektrik emisyon faktörünün $0,86 \mathrm{~kg}_{\mathrm{CO} 2} / \mathrm{kWsa}$ olduğu ele alınarak ECAM modellemesi sonuçlarında, Faz-1 aşamasında en yüksek sera gazı emisyonu Temmuz ayı 195.174 $\mathrm{kgCO}_{2}$ eşd./ay; Faz-2 aşamasında ise en yüksek sera gazı emisyonu Aralık ayı $226.573 \mathrm{kgCO}_{2}$ eşd./ay olarak tahmin edilmiştir. Tahmin edilen sonuçlara göre karışık atıksuların arıtıldığı arıtma tesisindeki sera gazı emisyonları, İtalya ve Romanya'da bulunan kentsel atıksu arıtma tesislerinden oldukça fazladır.

Saidan vd. (2019), Ürdün'ün Madaba kentinde yaptıkları çalışmada kentin su tesisleri için ECAM programı ile genel bir sera gazı emisyonu değerlendirmesi yapmışlardır. Çalışmada kentsel su arıtma tesislerinden kaynaklanan doğrudan ve dolaylı sera gazı emisyonlarının azaltılması amaçlanmıştır. Çalışma alanı olan Madaba'daki giriş suyu ve atıksuyu sistemlerinden kaynaklanan toplam sera gazı emisyonu yaklaşık y1lda 28.122 milyon $\mathrm{kgCO}_{2}$ bulunmuştur. Emisyonların \%62,4'ünün su kaynaklarından, \%37,6's1 atıksu arıtımından ve septik tanklardan taşınan atıksulardan oluştuğu belirtilmiştir [14]. Bu çalışma bulguları ile karşılaştırıldığında, sera gazı emisyonlarının yaklaşık \%90'1 elektrik enerjisinden; geri kalanı ise çamur bertarafı ve suyun geri kullanımından kaynaklanmaktadır.

De Gisi vd. (2017), kentsel atıksu arıtma tesisine ait çamur yakmadan oluşan sera gazı emisyonlarını incelemişlerdir. Çalışmada birincil ve ikincil çamur yönetimi, anaerobik çürütme, çamurun mekanik olarak susuzlaştırılarak gömülmesi ve enerji geri kazanımı ile akışkan yatak teknolojisine sahip çamur yakma yöntemini içeren sera gazı emisyonlarını ECAM 2.0 programıla değerlendirmişlerdir. Ek yakıt tüketiminin azaltılması için konvansiyonel yakma yöntemi yerine, entegre termal çamur arıtımı (kurutma + yakma) uygulanması sonucunda \%98 oranında sera gazı emisyonu azalmış olacağı tahmin edilmiştir [15]. Bu çalışma ile karşılaştırıldığında, Muratlı O.S.B A.A.T'nde sadece çamur susuzlaştrrma yöntemi olarak dekantör kullanılmakta olup, kamyon vasitasıyla bertaraf yöntemi uygulanmaktadır. Enerji tüketiminden sonra emisyona sebep olan kısmın, çamur yönetimine ait olduğu tahmin edilmiştir.

Ülkemizde ECAM modeli ile yayınlanmış çalı̧̧ma bulunmamaktadır. Ancak literatürde arıtma tesislerinin maliyet hesaplarında kullanılmış modellere göre sera gaz emisyon sonuçları aşağıda özetlenmiştir. Gülhan vd. (2018)'de yaptıkları çalışmada İstanbul'da bulunan 9 adet biyolojik atıksu arıtma tesisinin General Purpose Simulator (GPS-X) sürüm 6.5 model programıla sera gazı emisyonlarını hesaplamış, atıksu karakterizasyonu ve işletim prosesinin sera gazı emisyonu üzerine etkileri incelemişlerdir. Program sonuçlarına göre $\mathrm{CH}_{4}$ gazı emisyonu $45.497 \mathrm{tCO}_{2}$ eşd/yıl ve net $\mathrm{N}_{2} \mathrm{O}$ gazı emisyonu $697.942 \mathrm{tCO}_{2}$ eşd/yll olarak tahmin edilmiştir. Çamurdan enerji elde edilen dört tesiste, fosil yakıt tasarrufu ile kazanılan $\mathrm{CO}_{2}$ emisyonu miktarı $46.257 \mathrm{tCO}_{2} / \mathrm{yl}$ 'd dır. Dokuz tesisin toplam sera gaz1 emisyonu ise 697.182 $\mathrm{tCO}_{2}$ eşd/yıl'dır. İşletme prosesinin sera gazı emisyonunu belirleyici faktör olduğu görülmüştür [16]. Literatürdeki çalışmada kullanılan 4 tesiste biyogaz üretimi yapılmaktadır. 
Biyogaz üretimi yapılan tesislerde kaçak emisyonları arttırdığı tespit edilmiştir. Bu çalışmada, çamur bertarafında taşımadan kaynaklı toplam emisyonlar en fazla 19.153 $\mathrm{kgCO}_{2}$ eşd/ay ve yılda yaklaşık 229 bin $\mathrm{kgCO}_{2}$ eşd. olarak tahmin edilmiş olup, literatürde verilen çalışma verilerinden daha düşüktür.

Yapıcıoğlu (2018)'de yaptığı bir çalışmada, biri evsel diğeri endüstriyel olmak üzere iki A.A.T.'ne ait sera gazı emisyonu değerlendirmesi yapmıştır. Tesislerden kaynaklanan sera gazı emisyonlarını hesaplamak için kapalı çember metodu ve tesislerdeki sistem optimizasyonunu sağlamak için de Monte Carlo simülasyonu olmak üzere iki farklı yöntem kullanılmıştır. Çalışmada evsel A.A.T.'nde en yüksek emisyon miktarı $23.328 \mathrm{~kg} \mathrm{CO}_{2}$ eşd/gün; endüstriyel nitelikli atıksuyu olan Şanlıurfa Organize Sanayi Bölgesi Merkezi Atıksu Arıtma Tesisinde ise 977,76 kg CO 2 eşd/gün olarak hesaplanmıştır [14]. Bu çalışmada, $5.000 \mathrm{~m}^{3} /$ gün debi için tahmin edilen emisyon miktarları, Yapıcıoglu vd [17] çalışmasında incelenen $17.000 \mathrm{~m}^{3}$ ve $4.000 \mathrm{~m}^{3}$ kapasiteli tesislerde oluşan emisyon miktarları arasında yer almıştır.

Külah (2013), İzmir'de bulunan bir gida firmasına ait endüstriyel atıksu arıtma tesisinin sera gazı emisyonu değerlendirmiştir. Sera gazı emisyonu hesaplamak için ISO14064-I standartlarına göre Sera Gazı Protokolü seçilmiştir. Sonuçlarına göre, 2.178,35 ton/yıl doğrudan sera gazı emisyonu; elektrik kullanımından kaynaklı 903,37 ton/yıl ile dolaylı sera gazı emisyonları hesaplanmış [18] olup, bu çalışmadaki ECAM modeliyle hesaplanan sera gazı emisyonları sonuçları ile benzerlik göstermektedir.

\subsection{Karbon salınımlarının azaltılması için öneriler}

Yenilenebilir enerji kaynaklarının kullanımının arttırılmasıyla elektrik enerjisi geri kazanımı sağlayabilir, işletme maliyetleri indirgenerek sera gazı emisyonları bu yöntemle azaltılabilir.

Bölge içerisinde çamur yönetiminin yetersiz olması sebebiyle, taşımadan kaynaklı emisyonları azaltmak ve bertarafı sağlamak amacıyla çamur yakma sistemleri kurulabilir. Ancak yüksek yatırım maliyetleri sebebiyle tercih edilememektedir.

Ayrıca, düşük maliyetli ve uygulanabilirliği en basit karbon azaltma yöntemi ağaçlandırma çalışmalarıdır. Arıtma tesisi için ön görülen sera gazı emisyonu azaltma için ağaçlandırma hesapları yapıldığında bir yılda tahmini $\mathrm{CO}_{2}$ emilimini sağlamak için gerekli ağaç maliyeti 131.064 TL olmaktadır.

\section{Sonuçlar}

$\mathrm{Bu}$ çalışmada, WaCCliM organizasyonu tarafından geliştirilen ECAM v2.2 web tool programı ile Muratlı OSB A.A.T.'ne ait genel sera gazı emisyonu değerlendirmesi yapılmış olup, optimizasyon ve sera gazı emisyonlarının azaltılması yönünde çeşitli öneriler sunulmuştur. Yapılan bu çalışma, atıksu arıtma tesisinde elektrik enerjisi tüketimi ve çamur yönetimi bölümlerinden kaynaklı sera gazı emisyonu oluşumunu sergilemektedir.

Faz-1'e göre ilk senaryoda 3 firmanın bağlı bulunduğu Muratlı OSB A.A.T.'de 2019 yılına ait yaz ayları (Haziran, Temmuz ve Ağustos) verileri kullanılarak çalıştırılan ECAM program veri sonuçlarına göre, en yüksek sera gazı emisyonu
195.174 kgCO2eşdeğer/ay ile Temmuz ayında; en düşük sera gazı emisyonu ise $176.707 \mathrm{kgCO}$ eşdeğer/ay ile Haziran ayında oluştuğu tahmin edilmiştir.

Faz-2'de toplamda 18 firmanın bağlı olduğu Aralık ayında atıksu miktarının artmasıyla sera gazı emisyonlarını arttırıcı etki gösterdiği ortaya çıkmıştır. Kirlilik parametrelerinin sera gazı emisyonunu etkilediği ancak doğru orantılı olduğuyla ilgili bir şey söylenememektedir.

Bölgesel çamur bertaraf tesislerinin yetersizliğinden dolayı uzak mesafeli ve düşük maliyetli bertaraf tesisleri seçilmekte olup, taşımacılıktan kaynaklanan emisyonlar yüksek hesaplanmaktadır. Bir diğer önemli emisyon kaynağı elektrik enerjisi tüketimidir. Projelendirme hataları sonucu güçlü ekipmanların tükettiği enerji dolayısıyla yüksek işletme maliyetleri oluşturduğundan dolaylı emisyonlara neden olmaktadır.

Atıksu arıtma tesislerinde enerji verimliliğini arttırıcı ve emisyonları azaltıcı öneriler sırasıyla sunulmuştur. Rüzgar enerjisi, güneş enerjisi, biyokütle enerjisi gibi temiz enerji kaynaklarının kullanımı ve ağaçlandırma çalışmaları sera gazı emisyonu azaltımında düşük maliyetli yatırımlardır. Çamur bertarafı taşımacılığında, fosil yakıt kullanımı ve miktarından kaynaklanan sera gazı emisyonunda yakıt türünün değiştirilmesiyle emisyonlar indirgenebilir. Çamur kurutma gibi nihai bertaraf yöntemlerinin atıksu arıtma tesislerinde kullanımının yaygınlaştırılmasıyla enerji kazanımı arttırılarak aynı zamanda sera gazı emisyonu miktarları düşürülebilir.

\section{Teşekkür}

İşyerim olan ve bana bu çalışmayı yapmama izin veren Muratlı Organize Sanayi Bölge Müdürlüğü yetkililerine ve Atıksu Arıtma Tesisindeki yetkililere ve çalışma arkadaşlarıma katkılarından dolayı teşekkür ederim.

\section{Çıkar çatışması}

Yazarlar çıkar çatışması olmadığını beyan etmektedir.

\section{Benzerlik oranı (iThenticate): \%13}

\section{Kaynaklar}

[1] DSİ Genel Müdürlüğü, Etüd ve Plan Dairesi Başkanlığı, İklim Değişikliği Birimi İklim Değişikliği Çerçeve Sözleşmesi, Kyoto Protokolü ve Türkiye. http://www.dsi.gov.tr/iklim/sozlesmeler/cerceve_sozle sme_kyoto/iklim_degisikligi_cerceve_sozlesmesi_ve_ turkiye.pdf. Erişim 30.03.2021

[2] Elektrik Mühendisleri Odası, Tarımda Karbon Ayak İzi Sürdürülebilir Kalkınmanın Yeni Kuralı: Karbon Ayak İzi.https://www.emo.org.tr/ekler/49c17cab08ed10e_ek .pdf. Erişim 12.05.2021

[3] M. Öztürk ve A. Öztürk, BMİDÇS'den Paris Anlaşması'na: Birleşmiş Milletler'in iklim değişikliğiyle mücadele çabaları. Ömer Halisdemir Üniversitesi İktisadi ve İdari Bilimler Fakültesi Dergisi, $\quad$ 12(4), 527-541, 2019. https://doi.org/10.25287/ohuiibf.494667

[4] Resmi Gazete Sayısı:29003, Sera Gazı Emisyonlarının Takibi Hakkında Yönetmelik, T.C. Çevre ve Şehircilik Bakanlığı, Ankara, 2014. 
[5] S. Eggleston, L. Buendia, 2006 IPCC Guidelines for National Greenhouse Gas Emissions Inventories. Institute for Global Environmental Strategies, Japonya, 2006.

[6] Intergovernmental Panel on Climate Change. Climate Change 2007: the physical science basis, contribution of working group I to the fourth assessment. https://www.ipcc.ch/site/assets/uploads/2018/05/ar4_ wg1_full_report-1.pdf. Erişim 05.01.2021

[7] Muratlı Organize Sanayi Bölgesi. https://www.muratliosb.org/kurumsal/. Erişim 06.01 .2021

[8] Interntional Water Association. https://iwanetwork.org/about-us/. Erişim 06.01.2021

[9] M. Brander, A. Sood, C. Wylie, A. Haughton, J. Lovell ,Electricity-specific emission factors for grid electricity. Technical Paper, August 2011.

[10] Water and Wastewater Companies for Climate Mitigation, Ecam 2.2. methodology energy performance and carbon emissions assessment and monitoring tool. https://wacclim.org/wpcontent/uploads/2018/01/ECAM-Methodology-GuideJan-2019.pdf. Erişim 17.01.2021

[11] S. Eggleston, L. Buendia, 2006 IPCC Guidelines for National Greenhouse Gas Emissions Inventories. Institute for Global Environmental Strategies, Japonya, 2006.

[12] S. Eggleston, L. Buendia, 2006 IPCC Guidelines for National Greenhouse Gas Emissions Inventories. Institute for Global Environmental Strategies, Japonya, 2006.
[13] D. Fighir, C. Teodosiu, S. Fiore, Environmental and energy assessment of municipal wastewater treatment plants in Italy and Romania: a comparative study. Water, 11, 1611, 2019.https://doi.org/ 10.3390/w11081611.

[14] M. Saidan, H. J. Khasawneh., H. Aboelgna, S. Meric, I. Kalavrouziotis, A.H Jasem., B.O. Hayek, S. AlMomany, M. Al Malla, J.C. Porro, Baseline carbon emission assessment in water utilities in Jordan using ecam tool.Journal of Water Supply: Research and Technology -AQUA. 68.6, 2019. https://doi: 10.2166/aqua.2019.040

[15] S. De Gisi, A. Gherghel, G. Iannone, M. Notarnicola, C. Teodosiu, Evaluating the greenhouse gas emissions of a municipal wastewater treatment plant with sludge incineration. Polytechnic University of Bari - Gheorghe Asachi Technical University of Iasi, 2017.

[16] H. Gülhan, H. Özgün, M.E. Erşahin, R.K. Dereli, İ. Öztürk, İstanbul'daki biyolojik atıksu arıtma tesislerinin sera gazı emisyonunun modelleme metodu ile tahmini. Furat Üniversitesi Mühendislik Bilim Dergisi, 30(1), 59-67, 2018. https://dergipark.org.tr/tr/ download/article-file/433459

[17] P. Yapıcıoğlu, Atıksu arıtma tesislerinin sera gazı emisyonlarının minimizasyonu. Yüksek Lisans Tezi, Harran Üniversitesi Fen Bilimleri Enstitüsü, Türkiye, 2018.

[18] S. Külah, Greenhouse gas invertory for an industrial wastewater treatment plant. Master's Thesis, Dokuz Eylul University Graduated School of Natural and Applied Sciences, Turkey, 2013. 